\title{
Research on Agricultural Industrial Structure Optimization and Town Development in "Thirteen Five" Period
}

\author{
Lisha $\mathrm{Ma}^{1}$, Yangyang $\mathrm{Li}^{2}$ \\ ${ }^{1}$ Yunnan School of Economics and Management, Kunming, Yunnan, 650106 \\ ${ }^{2}$ Yunnan Techology and Business University, Kunming, Yunnan, 651700
}

KEYWORDS: Agricultural Industrial Structure; Optimization; Town Development; "Thirteen Five" Period

\begin{abstract}
Thirteen Five" period is in the process of China's modernization drive critical period, but the prospect of "Thirteen Five" period, China's economic and social development is faced with complex domestic and international environment test. With the deepening of scientific and technological innovation, agricultural industry structure adjustment and optimization constantly. Urbanization level is a measure of the level of a country's economic development an important symbol. The level of urbanization is closely related to both the level of a national industrialization and modernization, but also to its agricultural development and agricultural structure optimization closely. This paper studies the agricultural industry structure optimization "Thirteen Five" period of China's urbanization and the development of mutual relations.
\end{abstract}

\section{Introduction}

In recent years, the impact of globalization, urbanization, industrialization and urban-rural relations deepening, China's urban-rural relations have entered a new stage of development. With the acceleration of industrialization promotion, rapid development of urbanization, comprehensively promote the construction of rural, urban built-up area of space expansion, large-scale flow of urban and rural resources and mass migration of rural population to the "Twelfth Five Year Plan" period, a significant change in the relationship between urban and rural areas rural there have been dramatic changes. Faced with massive flows of socio-economic factors of development, land resources, spatial layout, urban and rural management system, also corresponding major change, rural transformation in rural issues at the core of the second five since become the focus of attention of the government and academia one of the issues. Meanwhile, with the urban and rural areas, new concepts such as urbanization made, all walks of life to discuss the issue for a long time for people of migrant workers, land reform, reform of the household registration system more enthusiastic, rural transformation and reform will be the focus of future development for some time. Rural Transformation refers to the process of rapid industrialization and urbanization in the face of rural-urban migration and socio-economic development factors interact, respond and adjust to the local actors, leading to rural areas in socio-economic, spatial organization, industry development Reconstruction model, etc.

Compared with the soon to be over, "1025" period, "Thirteen Five" period China is facing very different domestic and international environment, rural development at this stage is also important to modern agriculture transformation and upgrading, deepen rural reform period, to achieve the 
transformation of rural development "thirteen five" during the implementation of building a moderately prosperous society in far-reaching development goals. Based on the discussion of economics, sociology and geography and other disciplines mainstream views on rural development through the analysis of the main features of the new period for which the problems and the new situation of rural development, the corresponding planning tactics, in order to " rural development thirteen five "period provided inspiration.

\section{The Importance of "Thirteen Five" Period}

Whether it is from the environment and changes in the basic conditions of economic and social development facing the view, or from the requirements and objectives of economic and social development facing the view, "Thirteen Five" period will become an important stage in the critical period and affect long-term development of China. First, the "Thirteen Five" period is completed and the final sprint stage to achieve a comprehensive well-off society grand goal. Since the reform and opening up, from the "three-step" development strategy to the Chinese dream grand blueprint for China's development strategy of advancing with the times, it is also under the guidance of the development strategy of China's economic development to create the miracle. Party Congress refinement of the "three-step" strategy, the third step, that "in the 2000s to 20 years, concentrate our efforts on building a billion plus people of a higher level of well-off society." The party's 18 put forward the "two hundred years" goal and further refinement of the "three-step" strategy, the third step will be building a moderately prosperous society to building a moderately prosperous society, marked "Thirteen Five \% period will be building a moderately prosperous society in a critical juncture.

Secondly, the "Thirteen Five" period will be decisive to ensure the full achievement of deepening reform in key areas and key links crucial period. Third Plenary Session of the party's eighteen comprehensively deepen reforms to make the deployment, the time span covering the entire "Thirteen Five" period, many key reform tasks point are located in the "Thirteen Five" period.

In short, "Thirteen Five" period is in the process of China's modernization drive critical years for building a moderately prosperous society and accelerating socialist modernization and the great rejuvenation of the Chinese dream, are of great importance.

\section{The Concept of Agricultural Industrial Structure Optimization}

Changes and development of agricultural structure has its own internal rules. Agricultural Industrial Structure Optimization is a systematic project, must follow the evolution of the internal law of agricultural industry structure, its contents should contain two main aspects:

First, the agricultural industrial structure rationalization, refers to the process of development in the agricultural industry to the rational allocation of production factors, the relationship between the proportion of coordination between the various industrial sectors, promote the efficient use of factors of production; Second Agricultural Industrial Structure refers to the agricultural industry dynamic process structure from a lower level to a higher level of state development of the state, namely agriculture to high-tech industrial structure, high knowledge, high capital intensive, dynamic process high degree of processing and the development of high value-added.

Industry structure rationalization Agriculture is the foundation of agriculture Industrial Structure, only the first to reach the rationalization of sophistication. Rationalization of the industrial structure of agriculture in any country, any agricultural industrial structure optimization objectives pursued by the stage, while agriculture Industrial Structure is in the agricultural economy develops to a 
certain stage, the rationalization of industrial structure of agriculture to a certain extent became the Agricultural Industrial Structure Optimization aims. From the industrial structure of agriculture development, the industrial structure of agriculture of rationalization are interwoven, interacting, Agricultural Industrial Structure to achieve, you must first realize the rationalization of the industrial structure of agriculture, and the higher level of agricultural development of the industrial structure, its coordination of the requirements of industrial structure is higher. Coordination of agricultural industry structure adjustment is a constant proportional relationship between the industries and improves the process of inter-industry related degree, in fact, that in itself is a process of Agricultural Industrial Structure.

\section{The Essential Feature of Urbanization}

Urbanization is the transfer of rural population to urban areas continues to make steady decline in the rural population, the urban population growing process. With the development of productive forces, so that rural conditions and may be transferred to non-agricultural and non-agricultural areas, rural population shift out when conditions are ripe to become the urban population, resulting in decreasing the proportion of the rural population, the proportion of urban population gradually increase.

Urbanization is increasing the number of towns, cities and towns have been expanding process. With the improvement of the level of economic development, resource utilization efficiency requirements are high, but can improve the resource efficiency of production should be intensive modes of production, rather than extensive production. Urbanization is the mode of production from extensive to intensive process of transformation. Because the development of the city can quickly gather a variety of factors of production, resulting in agglomeration and scale, therefore, the result of urbanization is bound to increase the number of cities and towns, urban expansion.

Urbanization is a social and economic structure optimization process. With the advance of urbanization, traditional, backward, inefficient agricultural production will gradually be replaced by modern, advanced and efficient production of large-scale urban society, the primary industry declining, two, three industrial output value proportion continues rise, so that the continuous optimization of the production structure of society, upgrading; with urbanization, the proportion of primary industry employment will decline rapidly, secondary and tertiary industries, especially the proportion of tertiary industry increased significantly, so that the employment structure has been optimized; with urbanization, the urban population consumer group increased significantly, significantly reduced rural consumer groups, which led to the entire conversion from junior to senior social consumption structure.

\section{The Interaction of Agricultural Industrial Structure Optimization and Urbanization}

Through the analysis of the essential characteristics of the front of the urbanization of agricultural industrial structure optimization, we can get this conclusion: on the one hand, contribute to promoting the sustainable development of agriculture in the process of urbanization, unsustainable agricultural development will hinder urbanization process; on the other hand, the process of urbanization and agricultural development to adapt itself contribute to the sustainable development of agriculture, and the process of urbanization and agricultural development is not in harmony will hinder the sustainable development of agriculture. Both expressed as a mutual promotion and mutual restraint dependencies. 
Agricultural Industrial Structure Optimization not only does not hinder the process of urbanization, but there will be conducive to promoting the process of urbanization. First, sustained agricultural development, agricultural productivity and high efficiency, increase farmers' income and rural economic prosperity and to the development of this local rural non-agricultural industries have provided favorable conditions. Accelerate the development of rural non-agricultural industries is a prerequisite for the urbanization of small towns in rural development. Especially in our current level of economic development is low, by developing the rural township enterprises to promote the development of small towns, rural urbanization should be regarded as an effective way.

Promote the Rule of World Urbanization show: all urbanization normal country or region, the higher the level of urbanization, agriculture is more developed, such as the US, Japan and China's Taiwan region. Urbanization started to depend on agriculture, but urbanization and help to further promote the sustainable development of agriculture. Urbanization mechanism of action of the Agricultural Industrial Structure Optimization in:

Urban Development to promote agriculture from subsistence farming to market closed loop open agricultural conversion, in favor of increasing farmers' income. Urbanization in the provision for rural residents to use their own labor resources increase revenue opportunities, but also for the reduction and economies of scale to improve agricultural production costs provide the necessary basis; urbanization narrowed too much deviation and rural industrial and employment structure for adverse changes in the agricultural sector and increase farmers' income economic status to provide a strong guarantee; urbanization in the production of man to prepare the basic conditions for specialization and large-scale agriculture in the distribution of agricultural commercialization induced shift from rural to urban areas in the exchange of agricultural products to expand the market space, increase in consumption of household food consumption monetary expenditure. All of which are conducive to increasing farmers' income, thus contributing to the sustainable development of agriculture.

\section{Conclusion}

Optimizing industrial structure of agriculture is a necessary measure to achieve "production development", on optimizing the industrial structure should adhere to market-oriented, according to local conditions, step by step, play the principle of comparative advantage and sustainable development, taking into account economic, social and ecological benefits of organic unity the establishment of industry promoting agriculture and urban with rural development mechanism, the construction of efficient ecological agriculture industrial system, to promote structural adjustment of intensive production, the layout of regionalization, business industry, structural diversification, rural urbanization direction. In the specific policy, should further optimize the internal structure of agricultural production, improve the quality of agricultural economy; develop non-agricultural industries and the strategic shift of rural labor; improve the social service system in rural areas, promote the optimization and upgrading of industrial agriculture.

\section{Reference:}

[1] Fu Lifang, Assessment on Different Schemes of Industrial Structure Adjustment based on DEA, Journal of Northeast Agricultural University, 2004 (l): 47-53.

[2] .Jay.W Forrester. "Industrial Dynamics: A Major Break Through For Rescrission Maker" Business Reviw 36, (July - August) 1958 (4): 137-142.

[3] Tian Jun, Research of Multiple Criteria Random DEA Model and Application on Evaluation 
Investment, CHINESE QUARTERLY JOURNAL OF MATHEMATICS, 2000 No 6: 70-75.

[4] Chames A CooPer W.W, and Rhodes E. Measuring the efficiency of making units [J] .European Journal of Operational Research, 1978 (2): 429-444.

[5] Banker, R.D, Estimating Most Productive Scale Size Using Data Envelopment Analysis, European Journal of Operational Research 1984 (17): 35-44. 